\title{
How do the grain size characteristics of a tephra deposit change over time?
}

\author{
Nick A. Cutler ${ }^{1} \cdot$ R. T. Streeter ${ }^{2}$ A. J. Dugmore ${ }^{3,4,5} \cdot$ E. R. Sear ${ }^{1}$
}

Received: 18 July 2019 / Accepted: 3 June 2021 / Published online: 12 June 2021

(c) The Author(s) 2021

\begin{abstract}
Volcanologists frequently use grain size distributions (GSDs) in tephra layers to infer eruption parameters. However, for long-past eruptions, the accuracy of the reconstruction depends upon the correspondence between the initial tephra deposit and preserved tephra layer on which inferences are based. We ask: how closely does the GSD of a decades-old tephra layer resemble the deposit from which it originated? We addressed this question with a study of the tephra layer produced by the eruption of Mount St Helens, USA, in May 1980. We compared grain size distributions from the fresh, undisturbed tephra with grain size measurements from the surviving tephra layer. We found that the overall grain size characteristics of the tephra layer were similar to the original deposit, and that distinctive features identified by earlier authors had been preserved. However, detailed analysis of our samples showed qualitative differences, specifically a loss of fine material (which we attributed to 'winnowing'). Understanding how tephra deposits are transformed over time is critical to efforts to reconstruct past eruptions, but inherently difficult to study. We propose long-term, tephra application experiments as a potential way forward.
\end{abstract}

Keywords Laser particle size analysis · Taphonomy · Mount St Helens $1980 \cdot$ Tephra grain size distributions

\section{Introduction}

The grain size characteristics of tephra deposits are influenced by volcanogenic processes and atmospheric conditions during eruptions (Bonadonna et al. 2015; Bonadonna and Houghton 2005; Carey and Sparks 1986; Pyle 1989). Grain size distributions at a single location provide information on fragmentation mechanisms, eruption dynamics and sedimentation processes (airfall vs pyroclastic density

Editorial responsibility: K.V. Cashman

Nick A. Cutler

nick.cutler@ncl.ac.uk

1 School of Geography, Politics \& Sociology, Newcastle University, Newcastle upon Tyne, UK

2 School of Geography \& Sustainable Development, University of St Andrews, St Andrews, UK

3 School of Geosciences, University of Edinburgh, Edinburgh, UK

4 Department of Anthropology, Washington State University, Pullman, WA, USA

5 Graduate Center, City University of New York, New York, NY, USA currents, wind and/or column height changes, ash aggregation, etc.) Thus, eruptions for which there are no contemporary observations can be reconstructed from tephra layers preserved in the sedimentary record. The accuracy of these reconstructions is influenced by taphonomy: sound inferences can only come from tephra layers that record the initial deposit faithfully. Usually, it is assumed that grain size distributions (GSDs) in tephra layers are representative of the original deposit, but this is not necessarily the case. For example, in terrestrial settings, tephra deposits may be reworked by wind, surface runoff and slope processes, sometimes for a period of years or even decades (e.g. Liu et al. 2014; Panebianco et al. 2017; Wilson et al. 2011). Sub-aerial deposits could also be weathered (e.g. by frost action) or trampled by grazing animals. Geochemical alteration of the buried tephra layer could continue indefinitely. However, despite these observations, temporal changes in tephra GSD are not well understood (Buckland et al. 2020; Dugmore et al. 2020). We addressed this knowledge gap by comparing recent measurements of tephra grain size with similar measurements made decades earlier, shortly after the tephra was deposited. In this way, we aimed to calibrate decadal-scale changes in GSD experienced by a terrestrial tephra deposit. We anticipated systematic changes in the 
GSD due to 'winnowing' of the deposit, i.e. the loss of the finest particle size fraction due to aeolian erosion.

We conducted our study on the tephra layer produced by the eruption of Mount St Helens, Washington State, on 18 May 1980 (MSH1980 hereafter). The eruption produced $\sim 0.2 \mathrm{~km}^{3}$ of tephra (dense rock equivalent: Nathenson 2017) in two distinct phases: (1) an initial lateral blast that resulted in a co-ignimbrite plume (Eychenne et al. 2015; Hoblitt 2000; Hoblitt et al. 1981) and (2) a Plinian plume (Carey and Sigurdsson 1985; Eychenne et al. 2015; SarnaWojcicki et al. 1981). These phases led to the formation of distinct stratigraphic units in proximal deposits, most notably a grey, silty, basal unit associated with the lateral blast and a coarser, pumice- and lithics-rich unit formed from airfall deposits produced during the main, Plinian phase of the eruption (designated units A and B, respectively, by Waitt and Dzurisin (1981)). These units-which were treated as a single deposit in contemporary estimations of grain size distribution-were not observed in distal deposits, which were uniformly fine.

The MSH1980 tephra layer was particularly suited to a study of this type because the US Geological Survey (USGS) surveyed it within 2-3 days of the eruption, before it had been reworked (Sarna-Wojcicki et al. 1981). Carey and Sigurdsson (1982) also surveyed GSDs 2 months after the event. Samples collected by the USGS during the 1980 survey were used by Durant et al. (2009) to establish the GSDs of the fresh tephra deposit. In addition to some broadly predictable features (e.g. a decrease in mean particle size with distance from the vent), Carey and Sigurdsson (1982) and Durant et al. (2009) identified several distinctive characteristics in the GSDs:

a) The proportion of fine $(<62 \mu \mathrm{m})$ tephra was unusually high.

b) Fine grains fell from the Plinian umbrella cloud more rapidly than expected (attributed to ash aggregation and atmospheric processes: Carey and Sigurdsson 1982).

c) The GSDs exhibited marked bimodality in locations $<130 \mathrm{~km}$ from the vent (Fig. 1). This characteristic became less pronounced with distance: GSDs $>300 \mathrm{~km}$ from Mount St Helens were unimodal, with a slight negative skew.

Eychenne et al. (2015) subsequently analysed the biomodality of the MSH1980 tephra deposit in more detail,
Fig. 1 The grain size distributions (GSDs) of the MSH1980 tephra shortly after its deposition (after Carey and Sigurdsson 1982; Durant et al. 2009; Eychenne et al. 2015). Panel a shows the original sampling locations (open circles and diamonds) within $600 \mathrm{~km}$ of the vent, as well as isopachs (orange lines, with thickness in mm, after Sarna-Wojcicki et al. 1981). Our recent (2015) sampling locations are shown with red, filled circles. Original (1980) grain size distributions from representative proximal (b) and distal (c) sampling locations are shown for reference (refer to key for data sources). Locations $200 \mathrm{~km}$ from the vent and to the south of the main plume axis displayed marked bimodality in GSD (DZ20-3, DZ20-21). Proximal locations to the north of the plume (e.g. DZ20-32) had a more normal distribution, as did locations in a region of secondary thickening $~ 300-450 \mathrm{~km}$ from the vent (e.g. Davis 11)
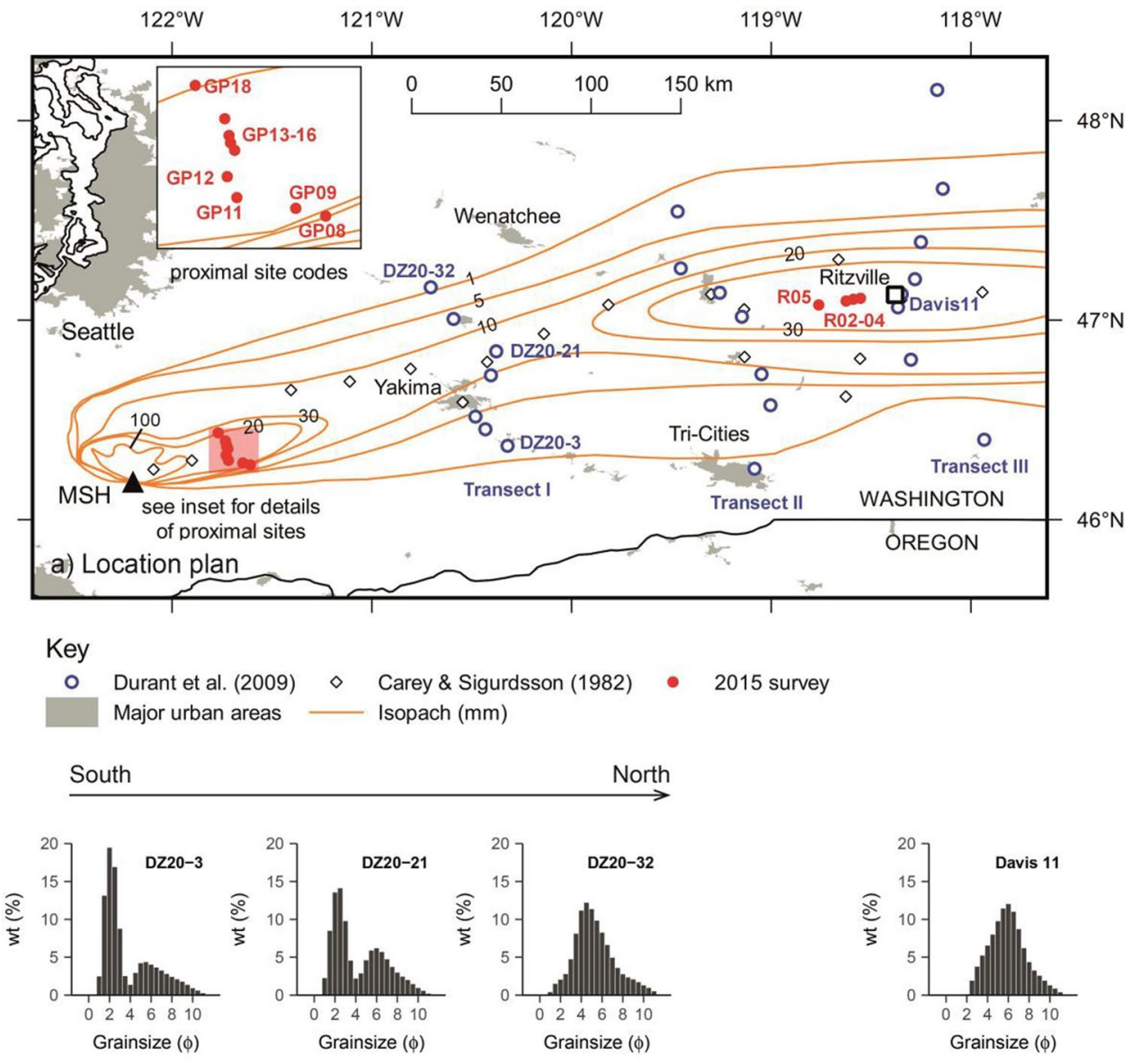

b) Transect I
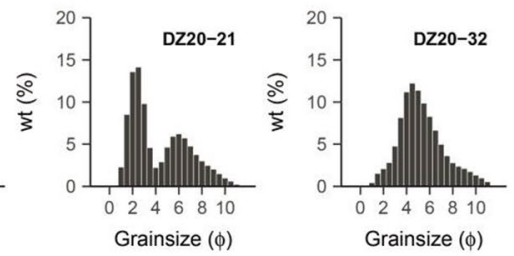

$\stackrel{\text { North }}{\longrightarrow}$

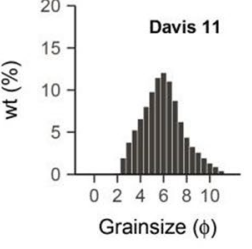

c) Transect III 
deconvoluting the tephra deposit into a coarse subpopulation that declined in size with distance from the vent, and a fine $(\sim 15 \mu \mathrm{m})$ subpopulation associated with the co-ignimbrite plume. They also found that bimodal GSDs were observed on the southern margin of the tephra deposit; to the north, the coarse fraction of the GSD was less pronounced and the GSDs were skewed unimodal (Fig. 1). They attributed these patterns to the complex eruption dynamics and meteorological conditions (cross winds).

Our previous study of the MSH1980 tephra layer indicated that its thickness was remarkably similar to the initial deposit (Cutler et al. 2018). We analysed samples from the same locations to see if GSDs were similarly representative, concentrating on 'proximal' sites $(\sim 40 \mathrm{~km}$ from Mount St Helens) and 'distal' locations $\sim 300 \mathrm{~km}$ from the vent, in a region of secondary thickening in the tephra deposit (SarnaWojcicki et al. 1981). Given that the thickness of the tephra layer was similar to the initial deposit in these locations, we expected to observe broadly the same patterns in grain size as Durant et al. (2009) and Eychenne et al. (2015). However, we anticipated a reduced proportion of fine material due to 'winnowing', i.e. the aeolian erosion of the finest fractions of the deposit. This effect would change the overall GSD, reducing negative skew and increasing the relative importance of the remaining coarse fraction (Fig. 2). We expected that winnowing would be most pronounced in the eastern parts of Washington State, as the tephra falling here was mostly fine in texture. Furthermore, this region has an arid, windy climate which would be expected to promote the loss of fine material (in the absence of secondary deposition of remobilised tephra).
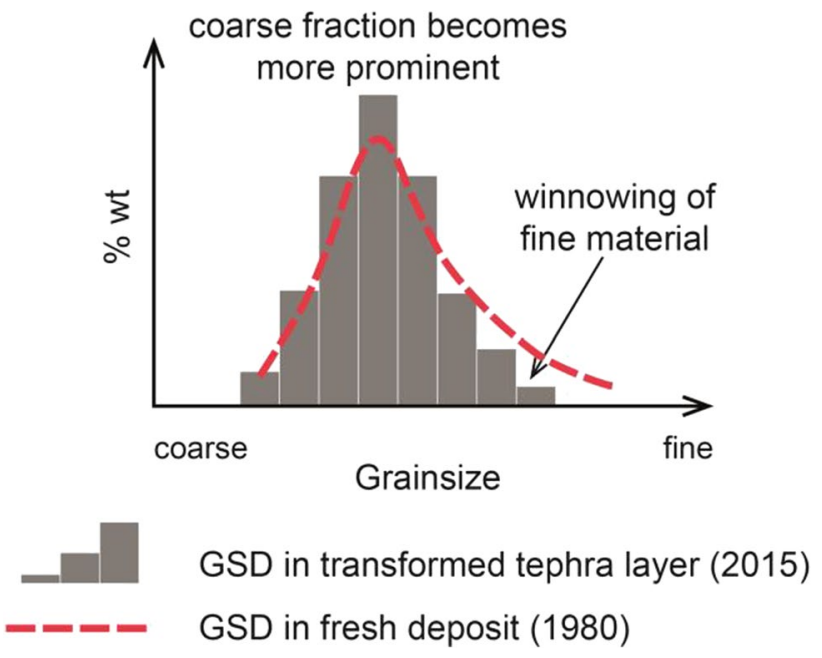

Fig. 2 Expected changes in grain size distribution over time. We anticipated a loss of the finest fraction of the deposit ('winnowing') in the absence of secondary deposition, and a corresponding increase in the proportion of the remaining coarse material

\section{Methods}

We collected samples from the MSH1980 tephra layer in August 2015. Our sampling was conducted in two regions: (1) proximal locations in the Gifford Pinchot National Forest (GPNF, 40 km from Mount St Helens), and (2) distal locations around Ritzville ( $\sim 300 \mathrm{~km}$ from the vent). The tephra layer in the proximal locations was covered by a litter layer a few centimetres thick. The distal sites were characterised by the presence of a biological soil crust (biocrust) of mosses and lichens 6-20 mm thick (further details of the sampling locations are given in Cutler et al. (2018)). We collected tephra from 13 locations (Fig. 1), taking three sub-samples from each location (39 samples in total). In each location, the samples were taken from areas of similar vegetation cover a few metres apart. In each case, we cut a $25 \times 25 \mathrm{~cm}$ square section into the soil with a carving knife, removed the overlying organic layer (proximal sites) or biological soil crust (distal sites) and excised the tephra layer, storing the excavated material in ziplock bags. We retained the biocrust from two distal sites for grain size analysis.

Durant et al. (2009) used laser diffraction particle size analysis (LDPSA) to establish GSDs (Malvern Mastersizer 2000, Malvern Panalytical, Malvern, UK). They measured grain size (the average of three repeat measurements) in the range $0.1-2000 \mu \mathrm{m}$ and presented their results on a Krumbein $(\Phi)$ scale with $0.5 \Phi$ bins. We also used LDPSA (Beckman Coulter LS230, Beckman Coulter, Brea, CA), based on a Fraunhofer diffraction model and measuring particles in the size range 0.375-2000 $\mu \mathrm{m}$. Following Carey and Sigurdsson (1982), we treated the tephra as a single unit. Three sub-samples were taken from each homogenised sample (i.e. our reported results are means of nine separate runs). We added $20 \mathrm{~mL}$ of deionised water and $5 \mathrm{~mL}$ of $5 \%$ sodium hexametaphosphate to each sub-sample and shook vigorously to suspend the tephra. Approximately $5 \mathrm{~mL}$ of suspended tephra was extracted with a pipette and placed on a glass dish. The sample was then rinsed into the particle size analyser dispersion unit through a 2-mm sieve with deionised water until an obscuration value of $8-12 \%$ was recorded. The measurement duration was $30 \mathrm{~s}$. Our results were reported in microns, but we selected bin sizes that corresponded to the phi scale used by Durant et al. (2009), for comparability. To account for site-to-site variability, we calculated average GSDs for proximal and distal locations, weighting the calculations by layer thickness.

\section{Results}

Our results showed that mean grain sizes in the tephra layer were similar to those observed in 1980 . The shape of the GSDs in the tephra layer also resembled the fresh (1980) deposit, although with differences in detail. 
The mean grain sizes we recorded were broadly consistent with those in the fresh (1980) deposit, particularly in the distal locations, although the recent proximal samples were somewhat coarser (Fig. 3). Intra-site variation in mean grain size was low; i.e. repeat measurements in the same sampling location were similar. Recent mean grain size in the proximal locations varied from $418 \pm 25 \mu \mathrm{m}$ to $919 \pm 72 \mu \mathrm{m}$, even though the distance to the vent was similar (39-46 km). Recent mean grain size at distal locations was much less variable $(\sim 28 \mu \mathrm{m})$.

As with mean grain size, the GSDs we observed did not vary much within sampling locations (i.e. sub-samples from each location were similar). The bimodal distribution observed by previous researchers was apparent in our proximal samples (Supp. Figure 1). The major peak in our samples occurred at a slightly coarser scale $(\sim 0 \Phi)$ and was less pronounced than the equivalent peak from a previous study (Carey and Sigurdsson 1982) (Fig. 4). A secondary peak at finer grades $(\sim 5 \Phi)$, similar to that observed by Carey and Sigurdsson (1982) and other researchers, was present in our samples. Proximal locations to the

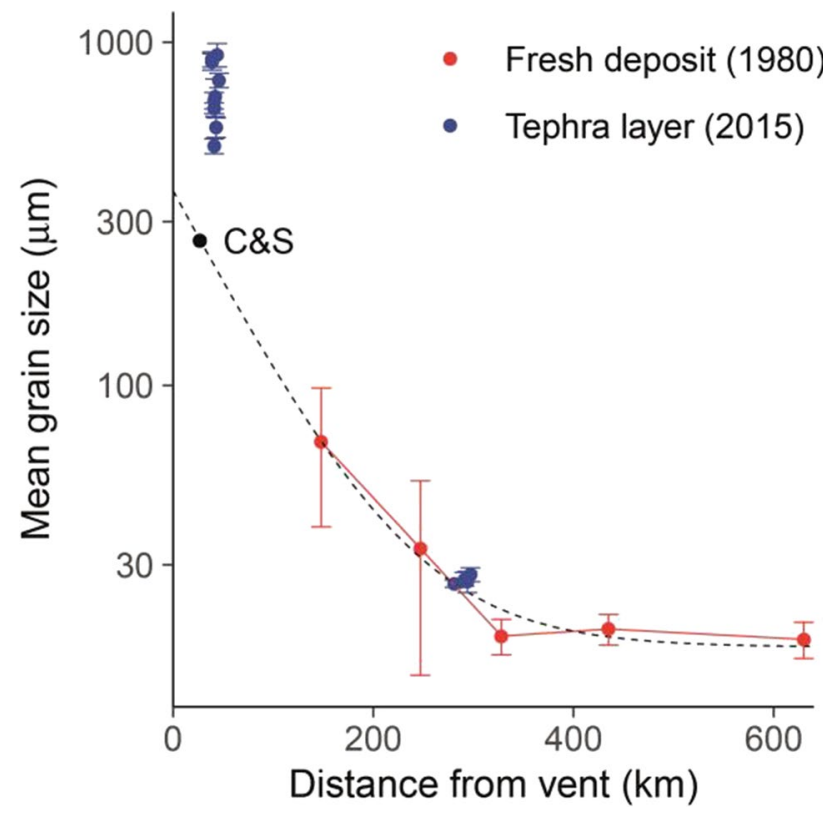

Fig. 3 Mean grain size by distance from vent. The red points are measurements of the fresh (1980) tephra deposit made by Durant et al. (2009) and averaged along five transects running perpendicular to the main plume axis (refer to Fig. 1 for the location of transects I-III). The blue points are our recent measurements of the tephra layer. The black point labelled ' $C \& S$ ' is an average value from sites $27 \mathrm{~km}$ from MSH (Carey and Sigurdsson 1982: statistical error not specified). The dotted line is an exponential decay curve fitted to Durant et al.'s (2009) fresh values, for reference. Standard deviation values for the recent (blue) measurements are small (Supplementary Table 2). The error bars on the red points show 1 SD from the mean $(\mathrm{N}$ varies) and represent the variation in grain size across the fresh tephra deposit (i.e. over distances of $10 \mathrm{~s}$ of $\mathrm{km}$ ) south of the main plume axis (GP08, -09, -11, and -12) had a significantly higher proportion of sand-sized grains (diameter $<4 \Phi$ ) than those to the north (GP14-16, -18) (proportions $86.8 \pm 1.4 \%$ vs $77.4 \pm 1.3 \%$, respectively; $t$ test: $t=5, \mathrm{p}=0.003$ ). There was also a trend of decreasing mean grain size from south to north (Supp. Figure 2).

The tephra layer from the distal sites was dominated by fine-grained material (silt or finer, i.e. $\geq 4 \Phi$ ). Our samples exhibited a unimodal distribution with a negative skew (Fig. 5d). The peak in the recent GSD was somewhat coarser than that observed in the 1980 samples $(\sim 5 \Phi)$. The finer end of the 1980 and 2015 GSDs $(>\sim 6 \Phi)$ from the distal sites was similar; however, the skew towards coarser particles was more pronounced (Fig. 5).

\section{Discussion}

The MSH1980 tephra layer has largely retained the grain size characteristics of the fresh (1980) deposit. Mean grain size varied predictably with distance from the vent (Fig. 3); bimodal GSDs were observed on proximal sites and unimodal GSDs in distal locations, as expected (Figs. 4 and 5; Supp. Figure 1). The primary (coarse) peak in the
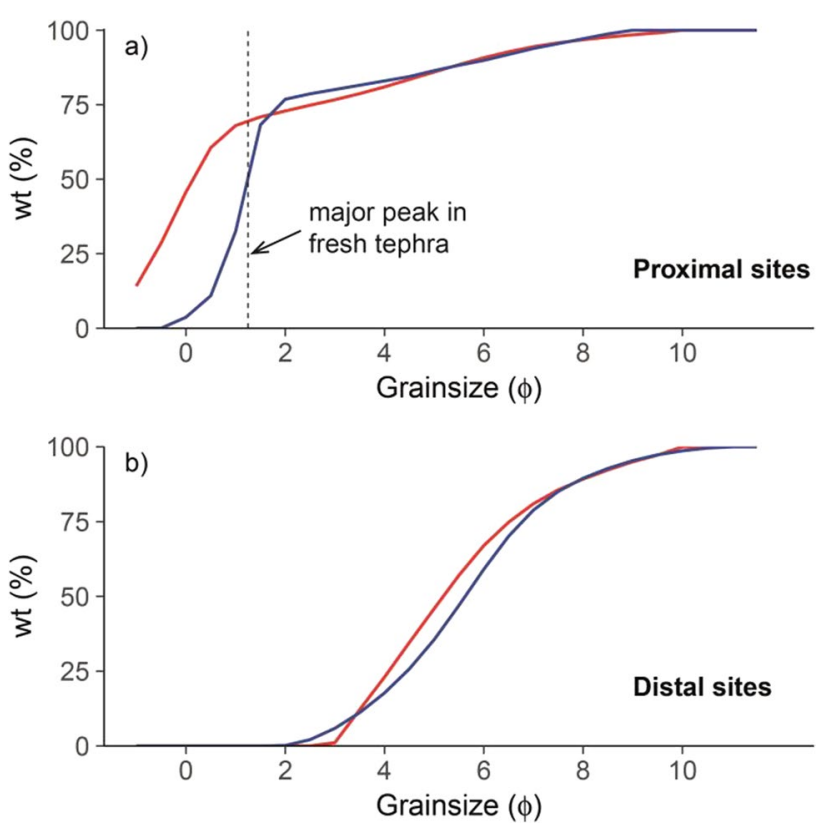

Fig. 4 Cumulative frequency plots of grain size for a proximal sites (approx. $40 \mathrm{~km}$ from MSH) and b distal sites $(\sim 300 \mathrm{~km})$. Our measurements of the tephra layer are weighted averages $(\mathrm{N}=7$ and 6, respectively) and are shown in red. Representative measurements from the fresh deposit ( taken from Carey and Sigurdsson's (1982) average GSD at $27 \mathrm{~km}$ from the vent and Durant et al.'s (2009) distal location Davis-11, at $311 \mathrm{~km}$ ) are shown in blue, for comparison. The peak identified in Eychenne et al.'s (2015) proximal GSDs is shown for reference in panel a 
Fig. 5 A comparison of GSDs from the fresh MSH1980 deposit (panels a and $\mathbf{c}$, shown in blue on the left hand side) and averaged GSDs of the tephra layer from comparable locations measured in 2015 (panels b and $\mathbf{d}$, shown in red on the right hand side). Proximal locations are on the top row, distal locations on the bottom. Panel a is from Carey and Sigurdsson (1982); panel c is after Durant et al. (2009)
Fresh deposit (1980)

Tephra layer (2015)
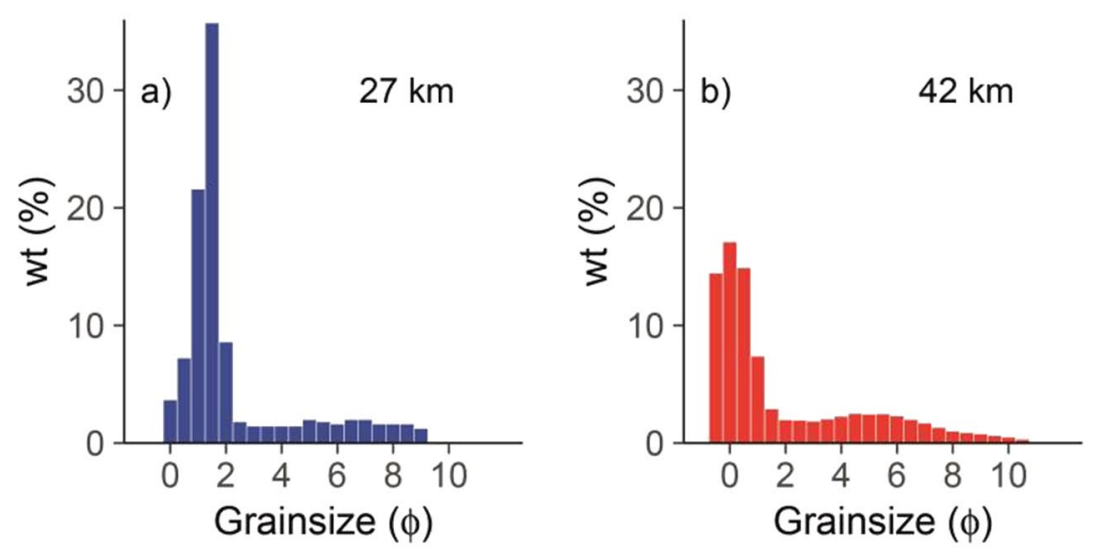

Proximal locations
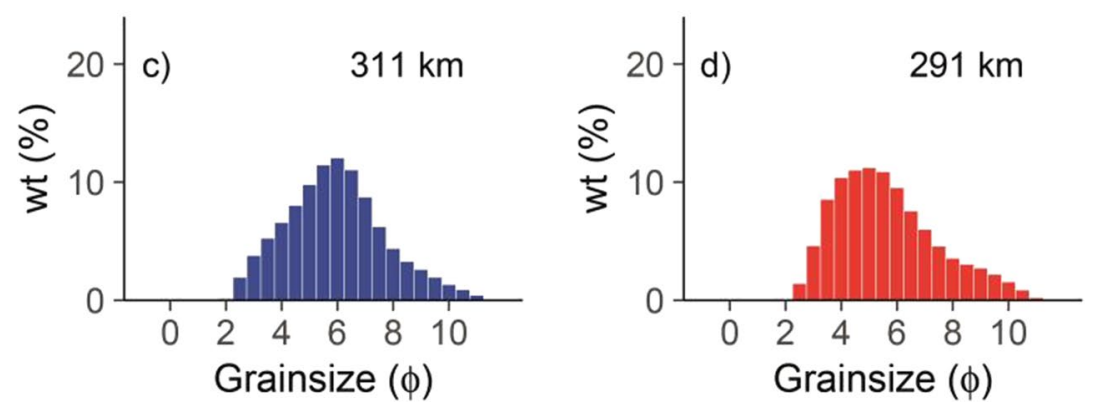

Distal locations

proximal tephra layer was less pronounced than the fresh deposit (Fig. 5), but this was probably because our sites were $\sim 15 \mathrm{~km}$ further from the vent than Carey and Sigurdsson's (1982). A transition from bimodal (south) to unimodal (north) distributions was not observed in our proximal locations, probably because our transect was much shorter than transects I and II established in 1980 (we only sampled the axial part of the plume, not the margins). However, a north-south gradient in grain size, consistent with the pattern observed by Eychenne et al. (2015), was apparent on our proximal sites (Supp. Figure 2). This trend-induced by the complex eruptive sequence and cross winds during the eruption-also accounted for the variability in mean grain size observed on the proximal sites.

Our findings are consistent with a survey of tephra layer thickness we conducted in 2015 (Cutler et al. 2018). This study indicated good preservation of the MSH1980 deposit. We attribute this preservation to factors that inhibited the remobilisation of the freshly deposited tephra (particularly the finer fractions). In the proximal sites, which are characterised by closed coniferous forest, it is likely that dense vegetation cover limited near-surface wind speeds and intercepted rainfall. High primary productivity led to rapid burial by organic litter (e.g. pine needles). These conditions are likely to exist in other temperate forests (Cutler et al. 2016, 2018). The distal sites are drier and windier and primary productivity is much lower, conditions that should facilitate mobilisation. However, rainfall shortly after the eruption, followed by rapid drying, led to the formation of a crust on tephra. This crust was reinforced by rapid colonisation of green algae, initiating biocrust formation and stabilising the tephra (Rayburn et al. 1984). In principle, this process could occur in other arid areas normally thought unsuitable for tephra preservation. However, biocrust formation may require fortuitous post-eruption rainfall and a minimum level of humidity. Further observations of biocrust formation on tephra substrates are required.

The overall fineness of the distal deposit may also have contributed to similarities between the fresh deposit and tephra layer. Recent research indicates that fine tephra fractions $(>\sim 4 \Phi)$ have cohesive properties that resist remobilisation by wind, particularly in the presence of moisture (Del Bello et al. 2021; Dominguez et al. 2020). Conversely, coarser particles are readily mobilised by wind. For two tephra deposits where aeolian remobilisation was measured under field conditions, del Bello et al. (2021) found that the greatest loss of material occurred in the 100-500 $\mu \mathrm{m}$ (1-3.5 $\Phi)$ size range.

The close correspondence between GSDs in the fresh deposit and tephra layer may also be due to the relatively short period of time that has elapsed since the eruption (35 years at the time of sampling). In the future, soil 
processes such as eluviation or bioturbation by burrowing animals may lead to alteration of the tephra layers and the loss of fine grains to other soil horizons (either above or below the current layer). Our field observations suggest that disruption of tephra layers by burrowing and grazing mammals is common in Washington State; churning of the tephra layer by soil invertebrates was not observed. However, to our knowledge, the physical transformation of tephra layers by soil invertebrates has not been studied before and is poorly understood.

Whilst the overall properties of the tephra layer were similar to the fresh deposit, there were differences in detail, notably the apparent coarsening of both the proximal and distal deposits. We attribute these differences to post-depositional transformation of the deposit. We suspect that the main alterations are due to the loss of fine material, i.e. winnowing. However, it is likely that other transformations have also occurred, e.g. a translocation of coarser material from the tephra layer to the overlying biocrust or the physical disruption of larger grains (or aggregations of smaller grains) by freeze-thaw action and/or trampling. There may also have been small systematic differences between the LDPSA devices used in the original studies and our analyses. For example, we note that the LDPSA device that we used relies on the Fraunhofer scattering model, whereas the Mastersizer

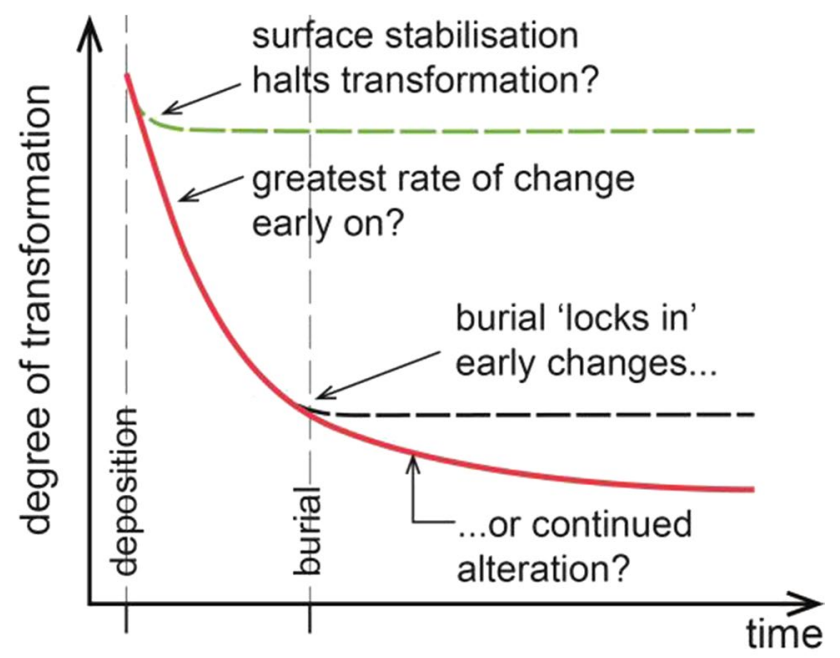

Processes

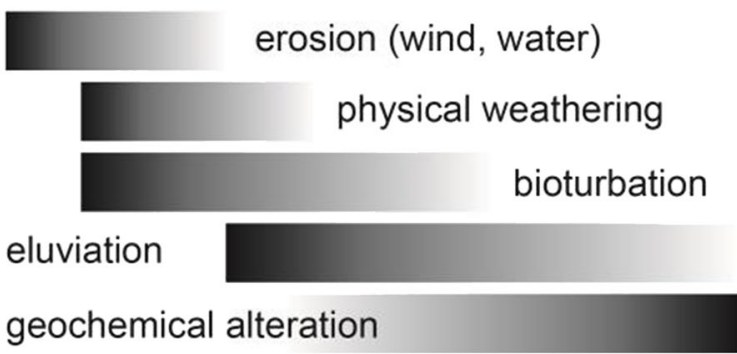

Fig. 6 Possible trajectories of change in tephra deposits over time uses a Mie model. These differences may account for some of the negative skew in our distal GSDs.

Our study did not explicitly consider the impact of stratigraphy on preservation: following earlier researchers, we treated the tephra layer as a single unit. We do not believe that the stratigraphy of the MSH1980 deposit impacted on preservation, as the stratigraphy recorded in 1980 was still present in our proximal samples. However, in principle tephra deposits with higher fractions of fine material may be more vulnerable to changes in GSD, particularly where upper horizons are finest.

\section{Conclusions}

The GSDs of samples from the MSH1980 tephra layer were very similar to those in the fresh deposit. Where a tephra layer has formed, it seems to faithfully represent the deposit from which it originated, most likely due to an environment that limited losses of fine material. If no contemporary observations of the MSH1980 eruption existed, it is likely that researchers attempting to infer plume dynamics from the tephra layer would reach similar conclusions to Durant et al. (2009) and Eychenne et al. (2015). However, the MSH1980 layer is relatively young and seems to have benefitted from fortuitous taphonomic circumstances. The extent to which the characteristics of the tephra layer will change over longer periods remains uncertain. In general terms, most change is likely to occur before burial, and certain processes, e.g. biocrust formation, could 'lock in' tephra layer characteristics at an early stage. However, it is quite possible that tephra layers undergo continued change, perhaps at a decreasing rate (Fig. 6) (Dominguez et al. 2020). Early changes (erosion, sorting, physical weathering) could be followed by bioturbation (both at the surface and in the soil profile) and hydrological and geochemical alteration. These processes matter because temporal changes in tephra layer characteristics have implications for volcanological reconstruction. If, for example, fine fractions are lost before, during and after burial, then inferences of eruption volume and dynamics may become increasingly unreliable with tephra layer age. This is a challenging process to investigate but could be addressed with experiments in which tephra is applied to plots and key parameters (e.g. layer thickness and GSD) are repeatedly measured over an extended period (years).

Supplementary Information The online version contains supplementary material available at https://doi.org/10.1007/s00445-021-01469-w.

Acknowledgements Financial support was provided by the National Science Foundation of America through grant 1202692 'Comparative Island Ecodynamics in the North Atlantic' and grant 1249313 'Tephra layers and early warning signals for critical transitions' (both to AJD). We are grateful for insightful comments provided by Julia Eychenne 
and one anonymous reviewer. We are also grateful for the assistance provided by Julia Eychenne and Adam Durant, who supplied grain size data for the initial deposit, and Will Hiles and Conner Morrison who conducted the grain size analyses. We also thank Ben Fitzhugh and Tim Kohler for fieldwork support, and Richard Waitt (USGS) for his advice, particularly regarding the selection of field sites and the interpretation of the MSH1980 tephra layer.

Open Access This article is licensed under a Creative Commons Attribution 4.0 International License, which permits use, sharing, adaptation, distribution and reproduction in any medium or format, as long as you give appropriate credit to the original author(s) and the source, provide a link to the Creative Commons licence, and indicate if changes were made. The images or other third party material in this article are included in the article's Creative Commons licence, unless indicated otherwise in a credit line to the material. If material is not included in the article's Creative Commons licence and your intended use is not permitted by statutory regulation or exceeds the permitted use, you will need to obtain permission directly from the copyright holder. To view a copy of this licence, visit http://creativecommons.org/licenses/by/4.0/.

\section{References}

Bonadonna C, Houghton BF (2005) Total grain-size distribution and volume of tephra-fall deposits. Bull Volcanol 67(5):441-456

Bonadonna C, Biass S, Costa A (2015) Physical characterization of explosive volcanic eruptions based on tephra deposits: propagation of uncertainties and sensitivity analysis. J Volcanol Geotherm Res 296:80-100

Buckland HM, Cashman KV, Engwell SL et al (2020) Sources of uncertainty in the Mazama isopachs and the implications for interpreting distal tephra deposits from large magnitude eruptions. Bull Volcanol 82:23. https://doi.org/10.1007/s00445-020-1362-1

Carey SN, Sigurdsson H (1982) Influence of particle aggregation on deposition of distal tephra from the May 18, 1980, eruption of Mount St. Helens volcano. J Geophys Res 87:7061-7072

Carey S, Sigurdsson H (1985) The May 18, 1980 eruption of Mount St Helens. 2: modelling of dynamics of the Plinian phase. J Geophys Res Solid Earth Planets 90(NB4):2948-2958

Carey S, Sparks RSJ (1986) Quantitative models of the fallout and dispersal of tephra from volcanic eruption columns. Bull Volcanol 48(2):109-125

Cutler N, Shears O, Streeter R et al (2016) Impact of small-scale vegetation structure on tephra layer preservation. Sci Rep 6:37260. https://doi.org/10.1038/srep37260

Cutler NA, Streeter RT, Marple J et al (2018) Tephra transformations: variable preservation of tephra layers from two wellstudied eruptions. Bull Volcanol 80:77. https://doi.org/10.1007/ s00445-018-1251-z

Del Bello E, Taddeucci J, Merrison JP, Rasmussen KR, Andronico D, Ricci T, Scarlato R, Iversen JJ (2021) Field-based measurements of volcanic ash resuspension by wind. Earth Planet Sci Lett 554. https://doi.org/10.1016/j.eps1.2020.116684
Dominguez L, Rossi E, Mingari L et al (2020) Mass flux decay timescales of volcanic particles due to aeolian processes in the Argentinian Patagonia steppe. Sci Rep 10:14456. https://doi.org/10. 1038/s41598-020-71022-w

Dugmore AJ, Thompson PIJ, Streeter RT, Cutler NA, Kirkbride MP, Newton AJ (2020) The interpretative value of transformed tephra sequences. J Quat Sci 35:23-38

Durant AJ, Rose WI, Sarna-Wojcicki AM, Carey S, Volentik ACM (2009) Hydrometer-enhanced tephra sedimentation: constraints from the 18 May eruption of Mount St Helens. J Geophys Res 114. https://doi.org/10.1029/2008JB005756

Eychenne J, Cashman K, Rust A, Durant A (2015) Impact of the lateral blast on the spatial pattern and grain size characteristics of the 18 May 1980 Mount St. Helens fallout deposit. J Geophys Res Solid Earth 120(9):6018-6038. https://doi.org/10.1002/2015JB012116

Hoblitt RP (2000) Was the 18 May 1980 lateral blast at Mt St Helens the product of two explosions? Philos Trans R Soc Lond A Math Phys Eng Sci 358(1770):1639-1661

Hoblitt RP, Miller CD, Vallance JW (1981) Origin and stratigraphy of the deposit produced by the May 18 directed blast. In: Lipman PW, Mullineaux DR (eds) The 1980 eruption of Mount St Helens, Washington, U.S. U.S. Department of the Interior, USGS, Washington D.C., pp 401420

Liu EJ, Cashman KV, Beckett FM, Witham CS, Leadbetter SJ, Hort MC, Guomundsson S (2014) Ash mists and brown snow: remobilization of volcanic ash from recent Icelandic eruptions. J Gerontol Ser A Biol Med Sci 119(15):9463-9480

Nathenson M (2017) Revised tephra volumes for Cascade Range volcanoes. J Volcanol Geoth Res 341:42-52

Panebianco J, Mendez M, Buschiazzo D et al (2017) Dynamics of volcanic ash remobilisation by wind through the Patagonian steppe after the eruption of Cordón Caulle, 2011. Sci Rep 7:45529. https://doi.org/10.1038/srep45529

Pyle DM (1989) The thickness, volume and grain size of tephra fall deposits. Bull Volcanol 51(1):1-15

Rayburn WR, Mack RN, Metting B (1984) Conspicuous algal colonization of the ash from Mount St Helens. J Phycol 18(4):537-543

Sarna-Wojcicki AM, Shipley S, Waitt RB, Dzurisin D, Wood SH (1981) Areal distribution, thickness, mass, volume, and grain size of air-fall ash from the six major eruptions in 1980. In: Lipman PW, Mullineaux DR (eds) The 1980 eruption of Mount St Helens, Washington, U.S. U.S. Department of the Interior, USGS, Washington D.C., pp 577-600

Waitt RB, Dzurisin D (1981) Proximal air-fall deposits from the May 18 eruption - stratigraphy and field sedimentology. In: Lipman PW, Mullineaux DR (eds) The 1980 eruption of Mount St. Helens, Washington. US Department of the Interior, USGS, Washington D.C., pp 601-616

Wilson TM, Cole JW, Stewart C, Cronin SJ, Johnston DM (2011) Ash storms: impacts of wind-remobilised volcanic ash on rural communities and agriculture following the 1991 Hudson eruption, southern Patagonia Chile. Bull Volcanol 73(3):223-239 